\title{
Application of android-based parking violations reporting system to support green campus program
}

\author{
Setiono $^{1, *}$ and Budi Yulianto $^{1}$ \\ ${ }^{1}$ Civil Engineering Department, Sebelas Maret University, Jalan Ir. Sutami 36A Surakarta 57126, \\ Indonesia
}

\begin{abstract}
The use of private vehicles by the academic community of Sebelas Maret University (UNS) is increasing every year. This has resulted in a reduced availability of vehicle parking spaces, thus impacting the emergence of illegal parking and violation of parking rules. In relation to the vision of the UNS rector mission to a green campus policy, it is therefore necessary to make vehicle parking arrangement on the campus area. The aim of study is to conduct parking management and develop a law enforcement parking vehicles system based on internet and android technology. An Android-based parking violation reporting application, called BuSet Parking App is developed. The analysis of vehicle parking characteristics results shows that the parking index value at motorcycles and cars parking areas are above 1.0 at a certain time, thus causing parking violations. The BuSet Parking App records the location and time of the parking violations incident along with the visual evidence of the infringement. This information is connected to the database system to detect offenders and to do the parking law enforcement process. With this technology, sustainable transport efforts by controlling the number of parking vehicles in the campus environment can then be done effectively and efficiently.
\end{abstract}

\section{Introduction}

The use of private vehicles in Indonesia is experiencing rapid growth with around $9.0 \%$ for motorcycles and passenger cars [1], along with the decline in public transport services [2] causing various problems in the community. Congestion, accident, pollution and parking area problems are unavoidable logical consequences. The UNS currently has 35,382 students and 1,658 academic staff. Most of the students and academic staff use private vehicles as a mode of transport to the campus [3]. Every day the number of motorcycles and cars that enter the campus are around 22,000 for motorcycles and 2,000 for cars. As the use of fuel consumption by automobiles is high, this will cause a high level of $\mathrm{CO}_{2}$ in the campus environment [4].

The number of students studying at the Faculty of Engineering UNS (FE UNS) is 2,448 people by 2018 [5] while the number of academic staffs is 34 people. FE UNS provides a parking area for its students and academic staff who bring motorcycles and cars to the

*Corresponding author: setiono@,ft.uns.ac.id 
campus. In relation to the high motorcycle users and potential for motorcycle theft, the motorcycle parking area is equipped with Radio Frequency Identification (RFID) technology [6]. This parking system helps the parking operator control the in-out flow of motorcycles in the parking area safely.

Field conditions show that from year to year the number of private vehicle users increased so that the available parking area is not sufficient to accommodate the parking needs. This resulted in the emergence of illegal parking and violation of parking rules. Figure 1 shows motorcycles and cars that do not park in the available parking area. To reduce the level of $\mathrm{CO}_{2}$ in the campus environment in accordance with green campus policy and minimise parking violation, it is then necessary to make a vehicle parking arrangement on the campus area.
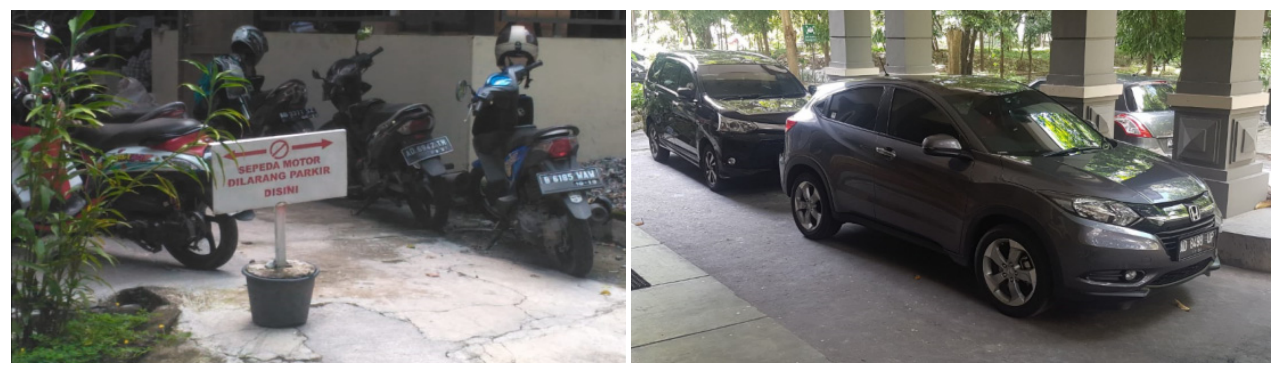

Fig. 1. Violation of parking rules.

The smartphone technology is advantageous for developing an application that helps humans with any daily life problems. It offers mobility and functionality such as Global Positioning Systems (GPS) module, a camera, and networking within android systems (open source systems) required by developers. Based on the Linux operating system, the android can communicate with other Linux based application such as Apache server, MySQL, and PHP.

The main objective of this research is to conduct parking management and develop an Android-based parking violation reporting application. The application can be used to capture parking violation incidents in real time as part of monitoring and controlling the parking system in the FE UNS neighbourhood.

\section{Research method}

The location of research is at FE UNS parking area. Figure 2 shows the location of motorcycle and car parking areas viewed on Google Maps.

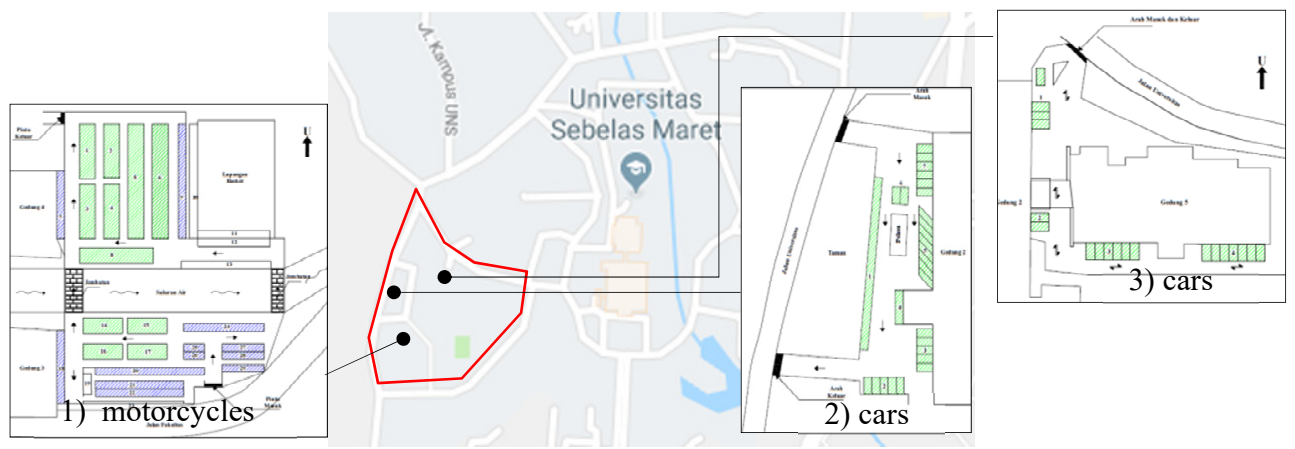

Fig. 2. Location of research at FE UNS. 
Analysis of vehicle parking characteristics is conducted to determine the parking capacity, parking accumulation and parking index [7]. Parking index shows the occupancy rate of parking, which can be used as a parameter to know the occurrence of parking violation. If the parking index value is higher than 1.0 that means a parking violation occurred.

As part of the law enforcement parking efforts in the campus parking area, a parking violation reporting application, called BuSet Parking App, is developed. The tools used for developing the application are Android Studio an official IDE for Android application and PHP5, JavaScript, and MYSQL for web development. The Google Maps library is also required to support the application relate to the information of incident location. Vehicle data belonging to students and academic staff of FE UNS that has been registered in the parking system are used by the application to report a parking violation.

\section{Results and discussion}

\subsection{Vehicle parking characteristics}

Surveys of recording the number of vehicles entering and exiting the parking area are carried out to calculate the parking accumulation and parking index. Surveys are conducted from 06:00 AM to 04:00 PM for both motorcycles and cars. Figure 3 shows the fluctuation of motorcycle parking accumulation and parking index at parking area 1 . The highest parking accumulation value is 804 motorcycles. During the time intervals of 09:45 AM - 11:30 AM, the parking accumulation exceeds the amount of parking capacity provided. Therefore, the value of index parking at that time exceeds the value of 1.0. This has an impact on the emergence of illegal parking and violation of parking rules. Several motorcycles are parked in the basketball area and in the alley between the parking space and the building, see Figure 4.
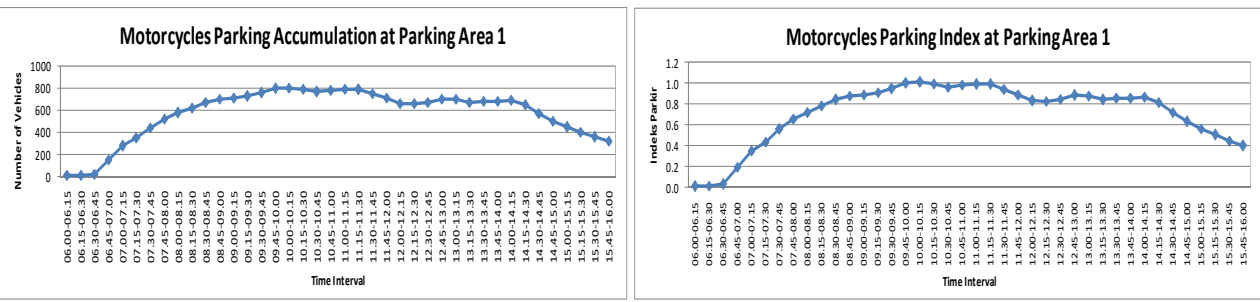

Fig. 3. Motorcycles parking accumulation and parking index.
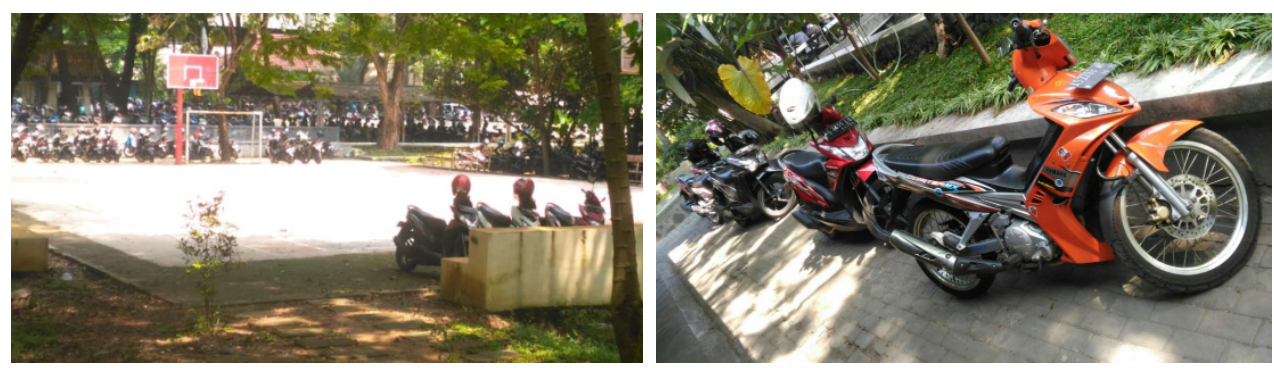

Fig. 4. Motorcycles parked in the basketball area and in the alley between parking space and the building.

Figure 5 shows the fluctuation of car parking accumulation and parking index at parking area 2 and 3 . The highest parking accumulation value is 42 cars and 20 cars, consecutively. During the time intervals of 01:00-02:15 PM and 09:45-10.45 AM, the parking accumulation 
exceeds the amount of parking capacity provided at parking area 2 and 3 , consecutively. Therefore, the value of index parking at that time exceeds the 1.0. This has an impact on the emergence of illegal parking and violation of parking rules. Several cars parked in the canopy area and in the alley between the parks, see Figure 6.
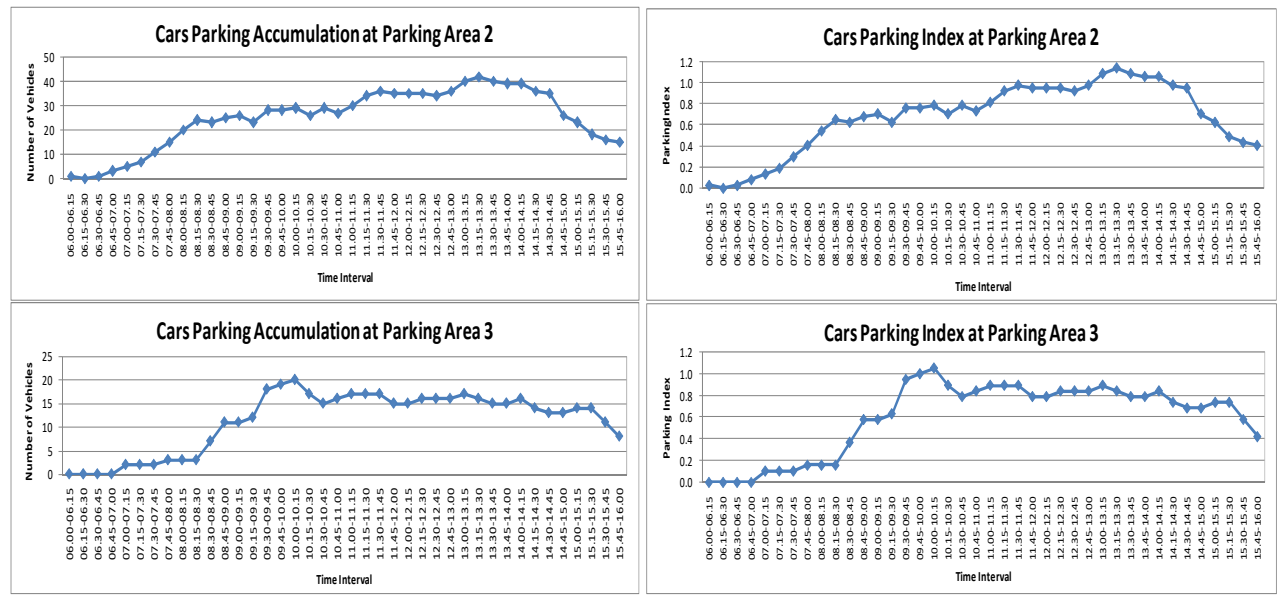

Fig. 5. Cars parking accumulation and parking index.
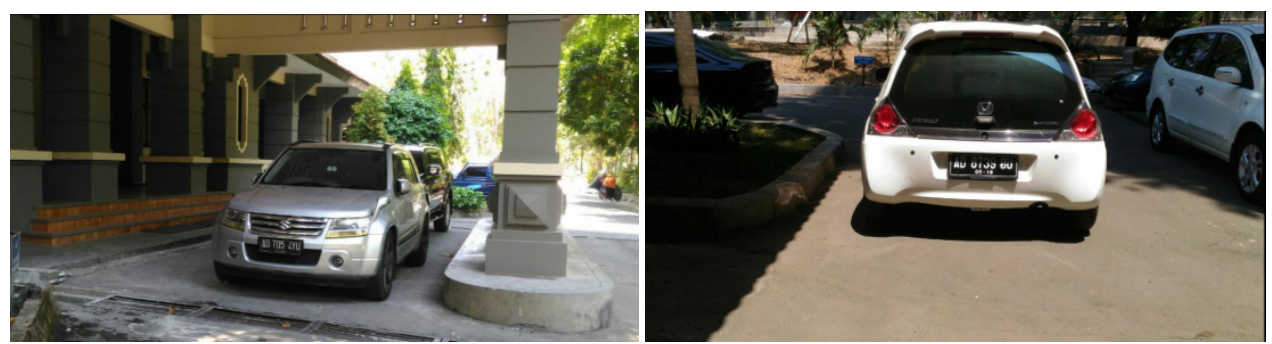

Fig. 6. Cars parked in the canopy area and in the alley between parks.

\subsection{BuSet parking android application}

The concept used by the BuSet Parking App refers to the previous work called E-Traffic Law Enforcement System application in Surakarta City with some changes according to its designation [8]. Figure 7 below shows the user interface design of the BuSet Parking App. The user interface is developed with Android Studio - version android of 5.0.2 Lollipop. The Figure $7 \mathrm{a}$ is the main form, where the user can log into the system with IMEI and a phone serial number. An internet connection is required to do this process. A user has to register to the system before he/she can use the facilities in the application, see Figure $7 \mathrm{~b}$. After the login process (Figure 7c), the user may use the application with the GPS turned on to capture the incident of parking violations; input the vehicle plate number and description of the incident (Figure 7d) and upload the data into the server. 


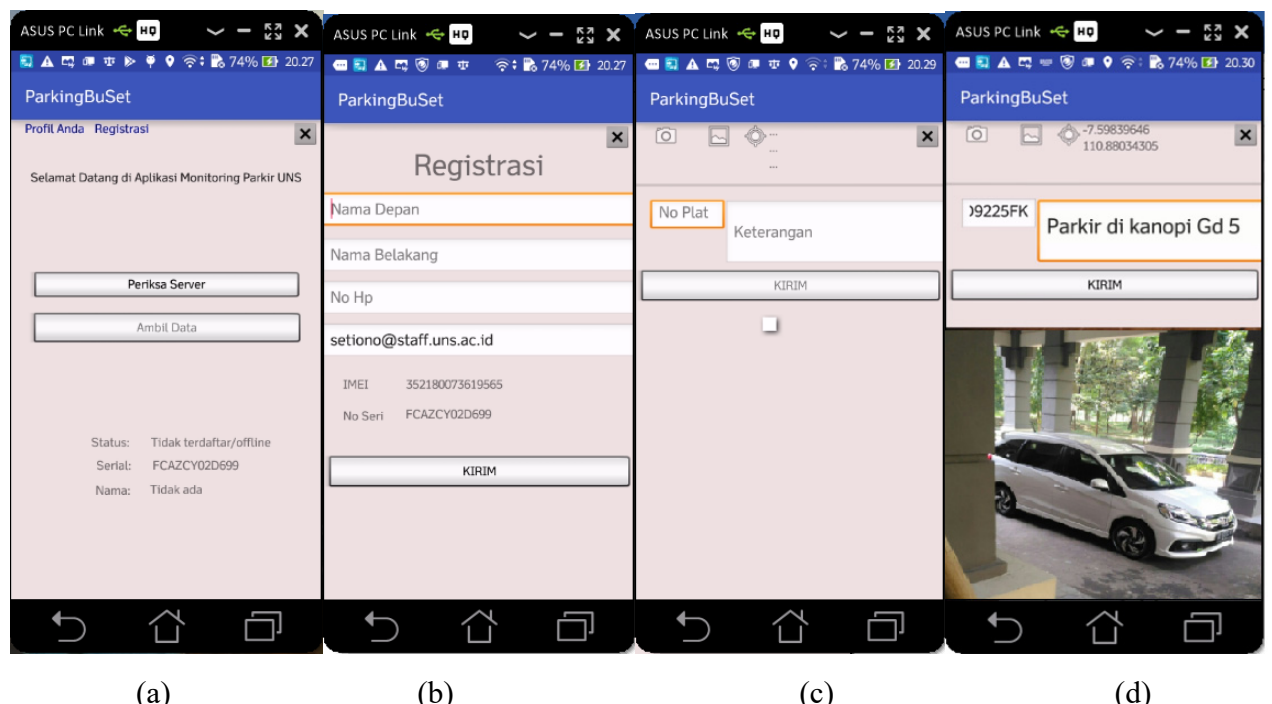

Fig. 7. Android Application user interface.

In communicating with the server, several scripts written in PHP5 are developed. The data parsed to/retrieved from the server must be in JavaScript Object Notation (JSON) format. JSON is a data format that uses human-readable text to express data objects containing attribute-value pairs.

\subsection{Database model}

The database for the application has four tables i.e. tblAdmin, tblUser, tblVehicle, and tblViolation. The entity relationship (E-R) diagram can be seen in Figure 8. The relationship of tblViolation towards tblUser and tblVehicles is Many to One. It implies that one vehicle can have more than one incident of violation as well as one user can record more than one incident.

The tblAdmin is used to store information of the administrator in managing the whole system such as verification of the registered users and sending notifications to vehicle's owners on parking violation through communication by phone (via SMS or WhatsApp).

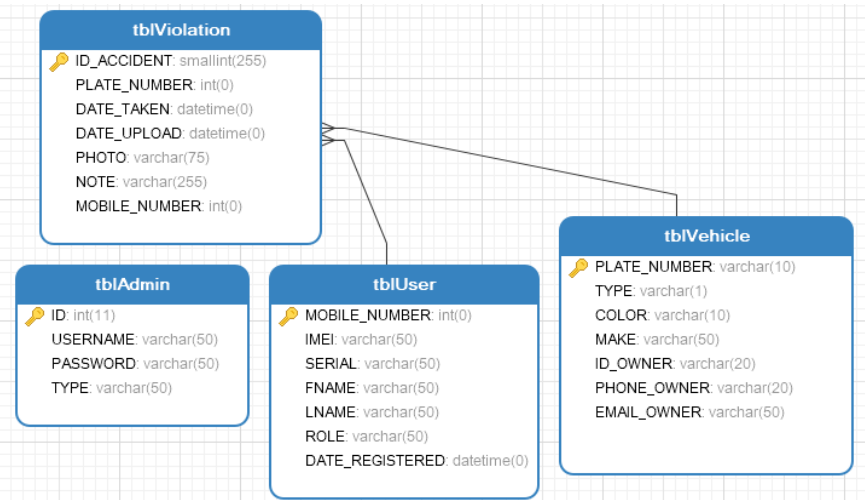

Fig. 8. Database model of BuSet parking app. 


\subsection{Web parking violation management systems}

The module of web user interface is built for administrative purposes. Figure 9 shows several appearances of it. The module provides administrator capability of manipulating (insert, edit and delete) the vehicles and user data. The module is developed using Codeigniter PHP framework and Bootstrap CSS library which has the responsive capability on any kind of machines (smartphones, tablets, and PCs).

The module with the support of Google Maps library can show the location of a parking violation incident and its picture as evidence [9]. It is also designed to have the capability of sending a notification to the vehicle's owner regarding that incident.

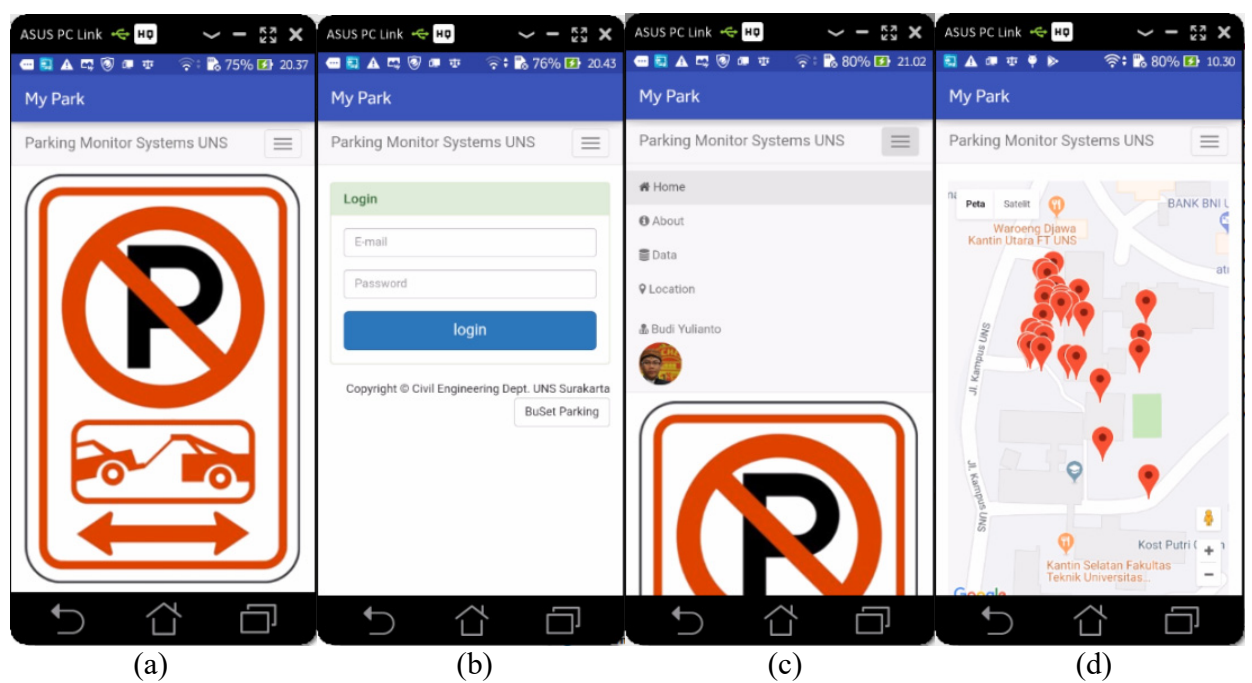

Fig. 9. Web user interface of BuSet parking app for administrative purpose a) view, b) login, c) database options, d) incident location data.

\section{Conclusion}

The analysis of vehicle parking characteristics results indicates that the parking index value at FE UNS parking area exceeds the value 1.0, thus causing parking violations. BuSet Parking App is developed for monitoring and controlling the parking system in the FE UNS neighbourhood. The application is able to record the location and time of the parking violation incidents along with the visual evidence of the infringement. This data will be used as evidence in punishing the offenders of the parking rules. The use of Android application makes it easier for the law enforcement department to conduct supervision, control and law enforcement against traffic violations due to its easy to use, simplicity, transparency and reliability.

The author would like to the LPPM of Sebelas Maret University for their support in funding this research.

\section{References}

1. Statistics Indonesia, Number of Motor Vehicles by Types, Indonesia 1949-2016, (Statistics Indonesia, Jakarta, 2018) 
2. D. Parikesit, B. Susantono, Strengthening the Role of Public Transport. Morichi, S., Archarya, S.R., (Eds) Transport Development in Asian Megacities - A New Perspective. Springer, 2013, p. 107-142, (2013)

3. Biro Perencanaan dan Informasi, Data dan Informasi Tahun 2017, University of Sebelas Maret, (2017)

4. B. Talbi, $\mathrm{CO}_{2}$ Emissions Reduction in Road Transport Sector in Tunisia, Renewable and Sustainable Reviews, Volume 69, March 2017, Pages 232-238, (2017)

5. UNS Executive Information Systems, Data Rekapitulasi Mahasiswa Aktif Fakultas

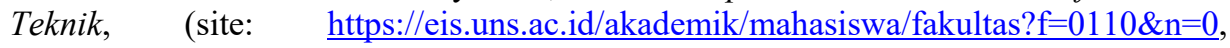
accessed: 23 April 2018)

6. C. M. Roberts, Radio Frequency Identification (RFID), Computers \& Security, Volume 25, Issue 1, February 2006, Pages 18-26, (2006)

7. N. Chen, L. Wang, L. Jia, H. Dong, H. Li, Parking Survey Made Efficient in Intelligent Parking Systems, Procedia Engineering 137, pages487-495, (2016)

8. B. Yulianto, Setiono, Android-based E-Traffic Law Enforcement System in Surakarta City, AIP Conference Proceedings 1941, 020056 (2018); doi: 10.1063/1.5028114, (2018)

9. B. Yulianto, Setiono, Web Application and Database Modeling of Traffic Impact Using Google Maps, AIP Conference Proceedings 1855, 060002 (2017); doi: $10.1063 / 1.4985525,(2017)$ 